\title{
Two-Stage Optimal Scheduling of Air Conditioning Resources with High Photovoltaic Penetrations
}

\author{
Dongxiao Wang ${ }^{\mathrm{a}}$, Runji $\mathrm{Wu}^{\mathrm{a}}$, Xuecong $\mathrm{Li}^{\mathrm{a}}$, Chun Sing $\mathrm{Lai}^{\mathrm{a}, \mathrm{b}^{*}}$, Xueqing $\mathrm{Wu}^{\mathrm{c}}$, Jinxiao $\mathrm{Wei}^{\mathrm{c}}$, $\mathrm{Yi} \mathrm{Xu}^{\mathrm{c}}$, Wanli $\mathrm{Wu}^{\mathrm{a}}$, Loi \\ Lei Lai ${ }^{\mathrm{a}}$ \\ ${ }^{a}$ Department of Electrical Engineering, School of Automation, Guangdong University of Technology, Guangzhou \\ China, 510006 \\ ${ }^{\mathrm{b}}$ School of Civil Engineering, Faculty of Engineering, University of Leeds, Leeds, LS2 9JT, UK. \\ ${ }^{\mathrm{c}}$ Guangdong Foshan Power Construction Corporation Group Co., Ltd, Foshan, China \\ * Corresponding author: c.s.lai@leeds.ac.uk
}

\begin{abstract}
Large-scale of controllable air conditioning loads have the potential to participate in distribution network operation via demand side control scheme. At the same time, distributed renewable energy resources are being deployed in distribution networks with increasing penetration rate. In this paper, a two-stage optimal scheduling method is proposed for distribution system with high photovoltaic penetration. The proposed scheduling method is decomposed into two stages to alleviate intra-day random variations of PV generation, electricity prices, and end-user load. In the day-ahead stage, this paper employs a mixed integer linear programming (MILP) method to achieve coordinated control of air conditioning loads, solar photovoltaic (PV) resources and battery energy storage systems (BESSs) under the target of minimizing system overall operation costs. A novel twoparameter lumped thermal model is introduced to more accurately describe the thermal dynamic process of the buildings, which is critical to meet the end users' thermal comfort in control process. In the real-time stage, a rolling horizon optimization approach is applied for minimization of imbalance costs between the day-ahead energy market and real-time energy market. Simulations are conducted on a radial distribution network, whose results verify that the proposed method can effectively reduce operation cost, lower peak demand and improve the PV penetration level in the distribution network.
\end{abstract}

\section{Keywords}

Air Conditioning Resources, Mixed Integer Linear Programming, Rolling Horizon Optimization, Two-stage Optimal Scheduling

\section{Nomenclature}

$\begin{array}{ll}A_{P V} & \text { Area of the PV panel exposed to solar radiation, } \mathrm{m}^{2} \\ C_{b u y}(t) & \text { Electricity purchase price from distribution network, } ¥ / \mathrm{kWh} \\ C_{\text {sell }}(t) & \text { Electricity selling price to distribution network, } ¥ / \mathrm{kWh} \\ C_{b u y, R T}(t) & \text { Electricity real-time purchase price, } ¥ / \mathrm{kWh} \\ C_{\text {sell,RT }}(t) & \text { Electricity real-time selling price, } Y / \mathrm{kWh}\end{array}$




\begin{tabular}{|c|c|}
\hline$C p_{a}$ & Indoor air heat capacity, $\mathrm{J} / \mathrm{kg}^{\circ} \mathrm{C}$ \\
\hline$C p_{w}$ & Indoor wall heat capacity, $\mathrm{J} / \mathrm{kg}^{\circ} \mathrm{C}$ \\
\hline$C^{E S}(t)$ & Operation cost of BESS, Y/kWh \\
\hline$C^{M}(t)$ & Power exchange cost with distribution system, ¥/kWh \\
\hline$C_{R T}^{M}$ & Real-time exchange cost with distribution network, $¥ / \mathrm{kWh}$ \\
\hline$C^{E S}(t)$ & Battery operation cost, $¥ / \mathrm{kWh}$ \\
\hline COP & Air conditioner coefficient of performance \\
\hline$E^{E S}(t)$ & Stored energy in BESS at time $t, \mathrm{kWh}$ \\
\hline$E_{I N I T}^{E S}$ & BESS initial power, $\mathrm{kWh}$ \\
\hline$E_{R}^{E S}$ & Rated capacity of BESS, kWh \\
\hline$G(t)$ & Solar irradiation forecast at time $t, \mathrm{~W} / \mathrm{m}^{2}$ \\
\hline$I C^{E S}$ & BESS investment cost, Y/kWh \\
\hline$L C N$ & The total life cycle number of BESS \\
\hline$M_{a}$ & Air mass amount, $\mathrm{kg}$ \\
\hline$M_{w}$ & Walls mass amount, $\mathrm{kg}$ \\
\hline$N$ & Normalization error \\
\hline$P_{a c}$ & Air conditioner rated power output, $\mathrm{kW}$ \\
\hline$P^{E S, D i s} / P^{E S, C h r}$ & BESS discharging/charging power, $\mathrm{kW}$ \\
\hline$P_{\max }^{E S, D i s} / P_{\max }^{E S, C h r}$ & Upper limits of BESS discharging/charging power, $\mathrm{kW}$ \\
\hline$P_{g_{b} b u y}(t)$ & Power purchased from external grid at time $t, \mathrm{~kW}$ \\
\hline$P_{g_{-} \text {sell }}(t)$ & Power selling amount to external grid at time $t, \mathrm{~kW}$ \\
\hline$P_{g_{-} b u y, R T}(t)$ & Real-time purchased from external grid at time $t, \mathrm{~kW}$ \\
\hline$P_{g_{-} \text {sell }, R T}(t)$ & Real-time power selling amount to external grid at time $t, \mathrm{~kW}$ \\
\hline$P_{g \max }$ & Power exchange upper limits, $\mathrm{kW}$ \\
\hline$\Delta P^{P V}$ & PV output forecast error \\
\hline
\end{tabular}


$P_{\text {uncontro_load }}(t) \quad$ Electricity load which is uncontrollable at time $t, \mathrm{~kW}$

$Q_{a c} \quad$ Cooling power of air conditioners, $\mathrm{J}$

$Q_{e x_{-} w_{-} r} \quad$ Heat exchange amount between walls and indoor air, $\mathrm{J}$

$Q_{\text {gain_a }} \quad$ Indoor air gained heat from ambient, J

$Q_{\text {gain_w }} \quad$ Indoor wall gained heat from ambient, J

$R_{e q} \quad$ Equivalent thermal resistance for a house envelope

$R_{w a} \quad$ Equivalent thermal resistance within environment and the indoor wall outer surface

$R_{w r} \quad$ Equivalent thermal resistance within indoor air and indoor wall inner surface

$S_{a c_{-} i n i t} \quad$ Operation status of air conditioners at initial time

$S_{a c}(t) \quad$ Operation status of air conditioners at time $t$

$\operatorname{SOC}(t) \quad$ BESS state of charge at time $t, \%$

$S O C_{\min } / S O C_{\max } \quad \mathrm{SOC}$ lower/upper limits

$T_{\text {amb_init }} \quad$ Temperature in the ambient at initial time, ${ }^{\circ} \mathrm{C}$

$T_{\text {amb }}(t) \quad$ Temperature in the ambient at time $t,{ }^{\circ} \mathrm{C}$

$T_{C}(t) \quad$ Temperature of the PV module at $t,{ }^{\circ} \mathrm{C}$

$T_{C_{\text {ref }}} \quad$ Reference standard temperature of the PV module, ${ }^{\circ} \mathrm{C}$

$T_{\text {rated }} \quad$ Rated temperature of the PV module, ${ }^{\circ} \mathrm{C}$

$T_{r_{-} \text {init }} \quad$ Indoor air temperature at initial time, ${ }^{\circ} \mathrm{C}$

$T_{r}(t) \quad$ Indoor air temperature, ${ }^{\circ} \mathrm{C}$

$T_{r}^{\min } \quad$ Indoor air temperature minimum required value, ${ }^{\circ} \mathrm{C}$

$T_{r}^{\max } \quad$ Indoor air temperature maximum required value, ${ }^{\circ} \mathrm{C}$

$T_{w_{-} \text {init }} \quad$ Temperature of indoor wall at initial time, ${ }^{\circ} \mathrm{C}$ 


$\begin{array}{ll}T_{w}(t) & \text { Temperature of indoor wall at time } \mathrm{t},{ }^{\circ} \mathrm{C} \\ T_{w}^{\min } & \text { Wall temperature minimum required value, }{ }^{\circ} \mathrm{C} \\ T_{w}^{\max } & \text { Wall temperature maximum required value, }{ }^{\circ} \mathrm{C} \\ \beta & \text { Influence coefficient of the temperature for energy conversion efficiency } \\ \eta_{i n v} & \text { Conversion efficiency of the inverter } \\ \eta_{P V} & \text { Energy conversion efficiency of the PV module } \\ \eta_{r e f} & \text { Reference energy conversion efficiency of the PV module under a standard } \\ \eta^{E S, D i s} / \eta^{E S, C h r} & \text { BESS discharging/charging efficiencies } \\ \tau & \text { Time interval } \\ \gamma^{E S} & \text { Battery lifetime depression coefficient } \\ \lambda_{1}, \lambda_{2} & \text { The Beta distribution shape parameters } \\ \mu_{x}, \sigma_{x}^{2} & \text { The mean and standard deviation } \\ \Delta x & \text { Electricity price/load forecast error }\end{array}$

\section{Introduction}

Under the context of smart grid, the modern distribution network is transitioning from traditional one-way passive network to two-way active distribution network with wide participation of distributed generation, demand response technology and automation control devices. Therefore, energy management is playing a more and more important role in distribution networks to help improve environmental quality and save energy in building operations. In residential and commercial buildings, energy management is especially important for end users to cut electricity bills and improve the living quality. Among all electric appliances and building services, the number of air conditioners (ACs) is increasing owing to the dropping upfront cost and end users' hunger for summer cooling. Large-scale air conditioning loads (ACLs) consume a large amount of electricity, which in one way causes short-period but sudden peak demand, particularly during the summer days with high temperature. Meanwhile, buildings equipped with air conditioning systems have an unusual thermal storage attributes similar to the buffering capacity in battery energy storage systems (BESS), which makes them have the potential to join the demand side management (DSM) schemes [1] Energex, an electric power distribution company in Queensland, Australia, is implementing the 
PeakSmart air-conditioner scheme which makes use of the demand management standard [2]

Moreover, in recent years, in order to protect the environment and cope with the future energy crisis, many countries gradually increase renewable energy generation. Distributed renewable energy has emerged as the new energy resources to meet end-users' demand in an optimal way and are gradually being widely applied in distribution system [3] The Renewables 2018 Global Status Report indicates that renewable energy is contributing $26.5 \%$ of global electricity production at the end of 2017 [4] Solar photovoltaic power, accompanied by mature technology and long-term sustainable clean energy, are being widely applied in the last ten years [5] According to the statistics in Clean Energy Council, more than 20\% of homes in Australia are provided electricity by solar PV by the end of 2018, with over 2 million installations [7] Although the unprecedented benefits in solar PV, it also brings up some issues due to its natural variability and stochasticity. Large-scale penetration of PV systems in the distribution system can cause reverse power flow, which brings negative impacts on power systems stability [8]

In previous research, many solutions have been proposed to schedule a large number of air conditioning loads via DSM schemes. In [9] an aggregated modeling and control framework for a large number of air conditioning loads is developed, which can handle load heterogeneity with statistical data in the load population and manage large-scale air conditioning systems to contribute some demand response services. In [10] a novel air conditioning system, consisting of a chilled water storage system and an air-conditioning system whose temperature and humidity are separately controlled, is designed for load shifting and power balance in the grid. In [11] the authors present an approach to model an inverter air conditioning system as one type of thermal battery, which achieves the compatibility of the inverter ACs with current dispatch models. In [12] the authors put forward a method to determine the size of battery energy storage systems and the number of photovoltaic panels in a building where heating ventilation and air conditioning systems are the primary electricity loads. Two benders decomposition strategies are adopted in the paper to solve the stochastic mixed integer linear programming (MILP) problem, which reduces the computation complexity. In [13] an optimal reactive power control method based on soft normally-open points in distribution systems is proposed, which schedules ACLs with direct load control and minimizes the impacts on users' thermal comfort and the active power loss. In [14] the authors propose a control scheme for the aggregated air conditioners based on the house thermal model. A couple of indexes are used to appraise the model performance, which demonstrates the effectiveness of the proposed control strategy.

In the meanwhile, great efforts have been done by the previous research to improve PV penetration level in distribution systems. In [15] a modified overvoltage protection scheme based on micro inverters is proposed to provide a reliable curtailment solution, which can help integrate PV resources without upgrading the grid infrastructure. In [16] the authors put forward a coordinated control strategy, which consists of the locally droop-based control and the distributed control, to regulate the charging and discharging status of BESSs. The control strategy is proved to be effective in increasing the penetration rate of PV in LV networks. In [17] a sizing strategy for BESS in the high PV penetrated distribution network is put forward to optimize the size of BESS. The authors build a system optimization model, which is composed of a physical battery model and an energy management system. In [18] a model based on wavelet transform and neural networks is applied to forecast the PV power, which is tested in a system that includes pumped hydro storage and demand response. In [19] the authors develop an energy management system, which can offer a flexible 
dispatch scheme for plug-in electric vehicles owners and achieve the collaboration between electric vehicles and PVs in low voltage systems. In [20] the authors build the connection of a conventional power transformer and a smart transformer in parallel, which is proved to be useful in improving the current quality in a weak grid with PV and wind turbine integrated energy systems.

By reviewing the literature, it can be found that previous research mainly focuses on the control scheme and dispatch strategy of air conditioning loads. In the meanwhile, many works are conducted to enhance PV penetration level in the distribution network by optimizing the size of battery energy storage systems or curtailing PV generation output. The above two issues are usually addressed separately by researchers. However, in a modern distribution network, air-conditioned buildings are integrating more and more solar PV resources. Therefore, how to address PV penetration issue with the help of air conditioning loads should draw researchers' attention. To the best of the authors' knowledge, no previous research has attempted to build an accurate model for air conditioning load to integrate the stochastic PV generation, while taking system uncertainties into consideration.

To address the remaining issues in previous work, this paper proposes a coordinated control scheme to schedule air conditioning loads, solar PVs and BESSs in the distribution network, which can efficiently reduce the system peak load and achieve higher PV generation penetration. The issue is formulated as an optimization problem to minimize the system operation cost while satisfying distribution network constraints, as well as the system components constraints. This mathematical problem is transformed into a mixed integer linear programming problem, which will lead to the optimized solution of battery energy storage operation status, as well as the ON/OFF status of air conditioners. System uncertainties, specifically PV generation fluctuations, electricity price, and daily load uncertainties are considered in system coordinated control scheme. Compared with previous research, the distinguished features and contributions of the paper are encapsulated as follows:

1) Instead of a simple and traditional one-parameter thermal model, this paper applies a more comprehensive two-parameter lumped thermal model to better describe the thermal dynamic process of air-conditioned buildings, which can best model the end users' thermal comfort.

2) A two-stage coordinated control scheme is proposed by considering the uncertainties of PV generation, daily load, and electricity prices. The objective is to minimize the operation cost in the day-ahead stage and system uncertainties are mitigated via a real-time rolling horizon optimization control strategy.

3) A grid-level control scheme is designed through directly controlling aggregated air conditioning loads, with the benefits of improving solar PV penetration level, reducing system peak demand, and satisfying end customers' thermal comfort constraints.

\section{Problem Description}

\subsection{System Components and Configuration}

As denoted in Fig. 1, the basic components of the system consist of controllable ACL groups, PVs, BESSs and other electric loads (non-controllable loads). Controllable ACL, as an important 
part of the electric loads, consumes a large amount of electricity in buildings. In the meantime, it has the capability to maintain power balance via demand response programs. From a practical point of view, an air-conditioned building can be pre-cooled or pre-heated to avoid peak electricity consumption. Integrated with other energy resources, the thermal buffering capacity in the airconditioned building can help providing desired ancillary service in power systems. It should be noted that in this paper the controllable loads primarily consist of air-conditioning loads when they are in cooling mode. PV can generate sustainable and clean energy, which is now installed in many green commercial buildings. BESSs can help managing energy usage through its charging/discharging characteristics. Other electric loads, such as lighting, which are noncontrollable, are occupying the other part of loads components.

Load controller (LC) in Fig. 1 controls the air conditioning loads in each aggregated group. Micro source controller (MC) controls BESSs and PV panels. Micro source controller center (MGCC) manages the LCs and MCs. MGCC further connects to the distribution management system (DMS), and exchanges information and power between them.

In the designed network, the electricity retail price is higher than solar PV feed-in tariff, which refers to the rate paid for electricity which is sold to the grid from solar PV panels. Thus, making full use of local solar energy is economical from the perspective of system operation. Given solar PV power uncertainties, the system can directly trade with an external grid to satisfy the demand side when local PV generations are not able to completely meet the system requirement. On the contrary, when system demand is lower than renewable output, the extra surplus power will be sold to the external grid.

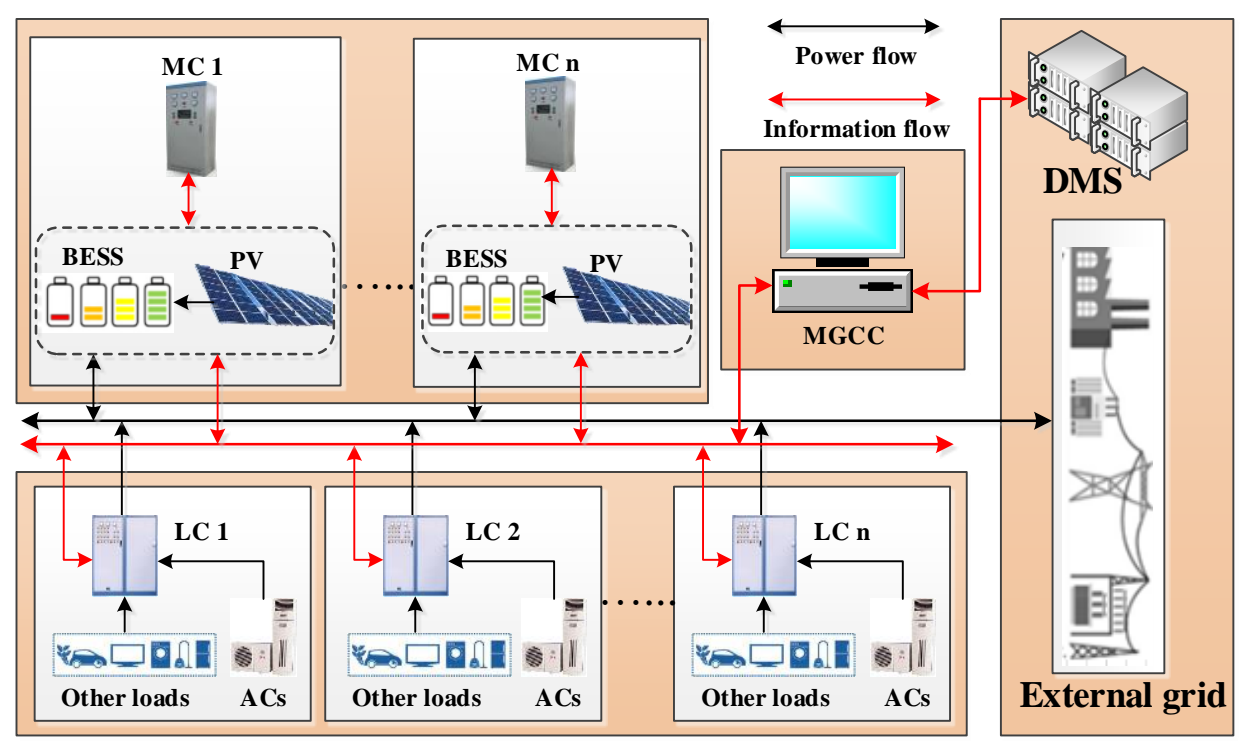

Fig. 1. The network structure including power flow and information flow.

\subsection{Proposed Strategy Introduction}

In this work, we propose a two-stage coordinated control scheme for scheduling the air conditioning loads in the distribution network. The overall objective aims to minimize system operation cost while reducing the peak demand of distribution network and improving the PV penetration level. 
A day-ahead scheduling approach is introduced for the proposed system at the first stage. The mathematical optimization problem is formulated as a large-scale mixed integer linear programming problem, which is able to be solved by different software, such as CPLEX and MATLAB. To better capture the thermal dynamic process of air-conditioned buildings, a more precise two-parameter thermal model is utilized here. In the day-ahead scheduling stage, day-ahead data, comprising ambient temperature, solar irradiation rate, electricity price, etc., are used as a system input. A realtime rolling horizon optimization strategy is executed at the second stage to mitigate the dynamic stochastic PV fluctuations, as well as electricity prices at 15-minute interval. At the real-time stage, the objective is imbalance cost minimization which is generated by the electricity market variations between two stages. A rolling horizon approach is employed in this work to the online optimization of the proposed operating strategy. Detailed processes and work procedures for each stage are introduced in Section 4.

\section{Components Modelling}

\subsection{ACLs}

ACL is playing a key role in the system. In order to participate in the scheduling scheme and accommodate the intermittent renewables, as well as maintaining the users' thermal comfort, the thermal conduction process in air-conditioned buildings needs to be comprehensively modelled. As denoted in Fig. 2(a), the simple one-parameter thermal conduction model is widely used in previous research [21] [22] In this one-parameter thermal model, the heat gain/loss of a building is calculated based on the difference between the environment and indoor temperature, considering only the equivalent thermal resistance of building envelope. After air conditioners are turned on, the thermal transmit will occur and finally reach an equilibrium point between the ambient and the building [23]

As shown in Fig. 2(b), a comprehensive two-parameter thermal model considers the thermal capacitance of walls, which is more complex and accurate [24] The two-parameter thermal lumped model is composed of two parts, one is in house thermal mass and another one is additional thermal mass inside the building with a great difference in thermal capacity, such as the walls.

According to [18] the change of internal air temperature will be significantly different with thermal capacity considered. In this paper, we employ the more complex and accurate twoparameter thermal model and improve its performance by calculating the coefficient of performance (COP) of an air conditioner, represented in Equation (5). COP indicates the ratio of air conditioner cooling energy to corresponding consumed electrical energy. Authors in [1] have demonstrated the effectiveness and superiority of the two-parameter thermal model. For the convenience of the readers, the detailed description of the two-parameter model is further explained below: 

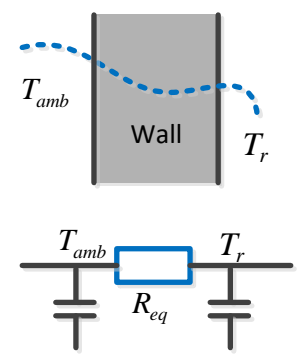

(a)
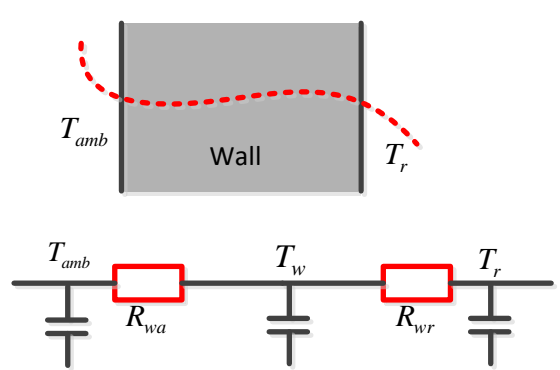

(b)

Fig. 2. Thermal models' denotation: (a) Previous one-parameter model (b) Proposed two-parameter model.

$$
\begin{aligned}
& \frac{d T_{r}(t)}{d t}=\frac{1}{M_{a} \times C p_{a}}\left[\frac{d Q_{\text {gait } a}(t)}{d t}-\frac{d Q_{\alpha-w-r}(t)}{d t}-\frac{d Q_{a c}(t)}{d t}\right] \\
& \frac{d T_{w}(t)}{d t}=\frac{1}{M_{w} \times C p_{w}}\left[\frac{d Q_{g a i n_{-} w}(t)}{d t}+\frac{d Q_{e x_{-}-w_{-} r}(t)}{d t}\right] \\
& \frac{d Q_{\text {gain_a }}(t)}{d t}=\frac{T_{a m b}-T_{r}}{\mathrm{R}_{e q}} \\
& \frac{d Q_{e x_{-}-r}(t)}{d t}=\frac{T_{w}-T_{r}}{R_{w r}} \\
& \frac{d Q_{a c}(t)}{d t}=C O P \times P_{a c} \\
& \frac{d Q_{\text {gain_w }}(t)}{d t}=\frac{T_{a m b}-T_{w}}{R_{w a}}
\end{aligned}
$$

Indoor air temperature change rate and wall temperature change rate are represented in (1) and (2). Equations (3)-(6) respectively show the heat gain variation rate from the environment to indoor air, the variation rate of heat exchange between walls and indoor air, the variation rate of air conditioners' cooling energy, and the variation rate of heat gain from the ambient to walls. The parameters in the above equations can be calculated based on the building physical data.

To simplify the calculation of the thermal parameters and ensure the unity of the MILP model, the thermal dynamic model is linearized here. The total scheduling time period in the control is 24 hours, which are divided into 96 uniform time intervals. In each time interval, the variables in the model, such as wall and indoor air temperature, can be assumed as a constant value. The linearization results are expressed in the following equations (7)-(10):

$$
\begin{aligned}
& T_{r}(t)=\left(1-\frac{1}{M_{a} \times C p_{a} \times R_{a q}}\right) \times T_{r_{- \text {init }}}+\frac{1}{M_{a} \times C p_{a} \times R_{e q}} \times T_{\text {anb_-init }}+\frac{T_{w_{\text {_init }}}-T_{r_{-} \text {init }}}{M_{a} \times C p_{a} \times R_{w r}}-S_{a c_{- \text {init }}} \times \frac{Q_{a c}}{M_{a} \times C p_{a}}, t=1 \\
& T_{r}(t)=\left(1-\frac{1}{M_{a} \times C p_{a} \times R_{e q}}\right) \times T_{r}(t-1)+\frac{1}{M_{a} \times C p_{a} \times R_{e q}} \times T_{a n b}(t-1) \\
& +\frac{T_{w}(t-1)-T_{r}(t-1)}{M_{a} \times C p_{a} \times R_{w r}}-S_{a c}(t) \times \frac{Q_{a c}(t-1)}{M_{a} \times C p_{a}}, \forall t \in[2, N] \\
& T_{w}(t)=T_{w_{-} \text {init }}+\frac{T_{\text {amb_init }}-T_{w_{-} \text {init }}}{M_{w} \times C p_{w} \times R_{w a}}+\frac{T_{r_{-} \text {init }}-T_{w_{\_} \text {init }}}{M_{w} \times C p_{w} \times R_{w r}}, t=1
\end{aligned}
$$




$$
T_{w}(t)=T_{w}(t-1)+\frac{T_{a m b}(t-1)-T_{w}(t-1)}{M_{w} \times C p_{w} \times R_{w a}}+\frac{T_{r}(t-1)-T_{w}(t-1)}{M_{w} \times C p_{w} \times R_{w r}}, \forall t \in[2, N]
$$

\subsection{PVs}

The PVs output power can be influenced by various meteorological factors, and the most important ones are solar irradiance and ambient temperature [25] According to [26] PV generation model can be described as follows:

$$
\begin{gathered}
P_{P V}(t)=A_{P V} G(t) \eta_{P V} \eta_{i n v} \\
\eta_{P V}(t)=\eta_{r e f}\left[1-\beta\left(T_{C}(t)-T_{C_{r e f}}\right)\right] \\
T_{C}(t)-T_{\text {amb }}(t)=\frac{T_{\text {rated }}}{800} G(t)
\end{gathered}
$$

\subsection{BESSs}

According to [21] [27] BESS operation cost usually is represented by its maintenance cost, which is considered in the optimization model. Here, a linear function is applied to describe the cost, shown in (14):

$$
C^{E S}(t)=\gamma^{E S} P^{E S, D i s}(t) \Delta t+\gamma^{E S} E^{E S}(t) \Delta t+\gamma^{E S} P^{E S, C h r}(t) \Delta t
$$

where, $\Delta t$ refers to the time interval when BESS energy is converted to power. The calculation of $\gamma^{E S}$ is given in [21]:

$$
\gamma^{E S}=\frac{I C^{E S}}{E_{R}^{E S} \cdot(L C N)}
$$

The following constraints should be met during BESSs operation:

$$
\begin{gathered}
E^{E S}(t+1)=E^{E S}(t)-P^{E S, D i s}(t) \Delta t / \eta^{E S, D i s}+P^{E S, C h r}(t) \Delta t \eta^{E S, C h r} \\
S O C(t)=E^{E S}(t) / E_{R}^{E S} \\
S O C_{\text {min }} \leq S O C(t) \leq S O C_{\max } \\
\left\{\begin{array}{l}
0 \leq P^{E S, D i s}(t) \leq P_{\max }^{E S, D i s} \\
0 \leq P^{E S, C h r}(t) \leq P_{\text {max }}^{E S, C h r}
\end{array}\right. \\
E^{E S}(t)=E_{I N I T}^{E S} \text { if } t=1
\end{gathered}
$$

Equation (16) presents battery storage capacity change rate, where the net energy injection and energy losses during charging/discharging process are considered. BESSs state of charge constraints are defined in Equations (17) and (18). Equation (19) denotes the charging/discharging power capacity is limited to the maximum value. Equation (20) means the initial energy stored in BESS at 
the start of operation.

\subsection{Uncertainties of PV Generation, Electricity Price and Load}

In this paper, PV power generation, electricity price, and daily load are considered as system uncertainties. As a commonly used method, historical data is taken from the day-ahead market, which is treated as correlated scenarios. Autoregressive integrated moving average model, a typical method in time-series-based methods, is used in this paper to generate correlated scenarios [28]

Beta distribution [29] is adopted to model PV forecast errors:

$$
f\left(\Delta P^{P V} ; \lambda_{1}, \lambda_{2}\right)=\Delta P^{P V \lambda_{1}-1}\left(1-\Delta P^{P V}\right)^{\lambda_{2}-1} N
$$

Gaussian distribution can be used to model load and electricity price forecast error [30] :

$$
f\left(\Delta x ; \mu_{x}, \sigma_{x}^{2}\right)=\frac{1}{\sqrt{2 \pi \sigma_{x}^{2}}} \exp \left[-\frac{\left(\Delta x-\mu_{x}\right)^{2}}{2 \sigma_{x}^{2}}\right]
$$

\section{Mathematical Formulation of Two-Stage Scheduling Model}

\subsection{Day-ahead Scheduling}

\subsubsection{Objective Function}

Based on the models of the various components, the proposed system model is given, which can be mathematically formulated as a mixed integer linear programming problem. The main objective in the system is set to minimize the total operation cost for all nodes in the system over the entire time period, which is mathematically formulated as Equation (23). As can be seen, the system operating cost is influenced by the power exchange between distribution network and external grid, corresponding solar PV feed-in tariff and electricity retail price, and battery energy storage system operation cost. To some extent, the net cost minimization could be achieved via reducing the power purchase from the external grid, which would ease the power supply pressure of power grid in the meantime. Furthermore, it means consuming as much power from local PV panels as possible, which will also help improve the penetration level of photovoltaic power generation.

$$
\min \sum_{t=1}^{N}\left(C^{M}(t)+C^{E S}(t)\right) \cdot \tau
$$

Specifically, the power exchange cost with distribution system is given as:

$$
C^{M}(t)=P_{g_{-} b u y}(t) \times C_{b u y}(t)-P_{g_{-} \text {sell }}(t) \times C_{\text {sell }}(t)
$$

It is worth noting that $P_{g_{-} b y}$ and $P_{g_{-} \text {sell }}$ are the decision variables in Equation (24). Both of them are varying over time and will further affect the whole time period operating cost. 


\subsubsection{Constraints}

To maintain the stable system operation in the proposed system, constraints including load balance constraints and components operation constrains should be satisfied. The specific constraints that need to be satisfied are given below:

1) Power balance constraints

Under normal operating conditions, the power supply and power consumption in the distribution network need to keep balance at any time. Meanwhile, the power exchange amount with external grid has to be less than the maximum power capacity of the distribution network. Equations (25)(27) describe the above power balance constraints as follows:

$$
\begin{gathered}
P_{\text {uncoutro_load }}(t)+P_{a c} \times S_{a c}(t)=P^{E S, C h r}(t)+P_{g_{-} b u y}(t)-P^{E S, D i s}(t)+P_{S}(t) \\
0 \leq P_{g_{-} \text {sell }}(t) \leq P_{g \max } \\
0 \leq P_{g_{-} \text {buy }}(t) \leq P_{g \max }
\end{gathered}
$$

2) Thermal comfort constraints

Before scheduling the controllable ACLs, ensuring customers' thermal comfort should be considered as the critical part [31] The users' thermal comfort constraint in this paper is described by the indoor air temperature range, which is shown in Equation (28). Moreover, the wall temperature range is expressed in Equation (29). Here, air-conditioners are assumed to work at rated power once turned on. As shown in (30), binary integer is used to represent the operating states of air-conditioners, where $S_{a c}=1$ means that ACs are ON, $S_{a c}=0$ means OFF.

$$
\begin{gathered}
T_{r}^{\min } \leq T_{r}(t) \leq T_{r}^{\max } \\
T_{w}^{\min } \leq T_{w}(t) \leq T_{w}^{\max } \\
S_{a c}(t)= \begin{cases}1, & \text { ON } \\
0, & \text { OFF }\end{cases}
\end{gathered}
$$

3) BESSs and PVs constraints

Section 3 already gives the constraints of PVs and BESSs, where we introduce the modeling of the components, specified in (11)-(20).

\subsection{Real-time Rolling Horizon Optimization Model}

In the real-time stage, system uncertainties are accommodated into the optimization model. In order to alleviate the initial forecast discrepancy and deal with uncertainties in the system, rolling horizon optimization strategy is employed here, whose main procedures are described below in Fig. 3. In this paper, the time interval is set to be 15 minutes.

- At the first scheduling interval, forecasted solar PV output power, forecasted electricity load, electricity price, next day ambient temperature, etc., are input into the system. Then a group of scheduling results are calculated by the day-ahead MILP model (e.g. $S_{a c}, T_{r}$ and $T_{w}$ ) with the 
aim of getting the minimum net cost.

- At the next interval, the input data are updated, specifically newly forecast solar PV power, daily load, time-of-use electricity price, previous step generated parameters $T_{r}$ and $T_{w}$, etc. Then the MILP model optimizes the objective function again while generating a new group of parameters for next time step.

- At each scheduling interval, the control window is moving forward by one-time step. The above procedures are repeated until the last scheduling interval is completed.

The objective in this stage is to get the minimized imbalance cost, which is generated by the deviation between day-ahead electricity market and real-time electricity market. The formulation is defined as:

$$
\min \sum_{t=1}^{N}\left(C^{M}(t)-C_{R T}^{M}(t)\right) \cdot \tau
$$

The calculation of $C_{R T}^{M}$ is denoted as:

$$
C_{R T}^{M}(t)=P_{g_{-} b u y, R T}(t) \times C_{b u y, R T}(t)-P_{g_{-} \text {sell, }, R T}(t) \times C_{\text {sel }, R T}(t)
$$

In the real-time stage, the previous sub-section constraints should be met as well. The flowchart of two-state optimal scheduling control scheme is given in Fig. 4.

Time Window

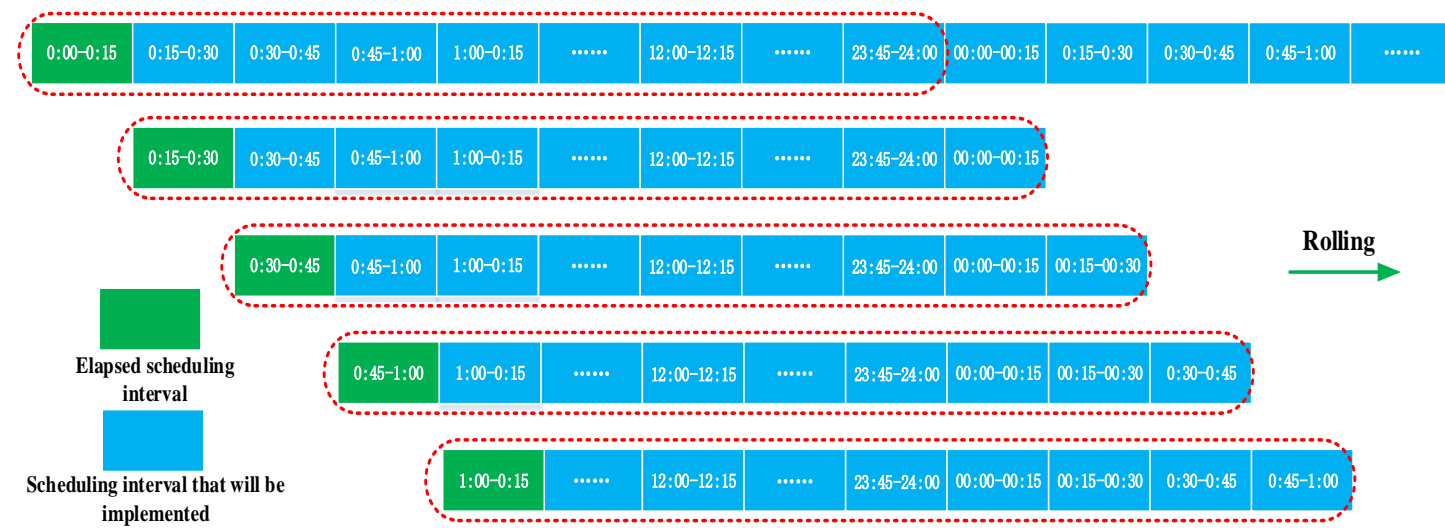

Fig. 3. Process denotation of rolling horizon optimization. 


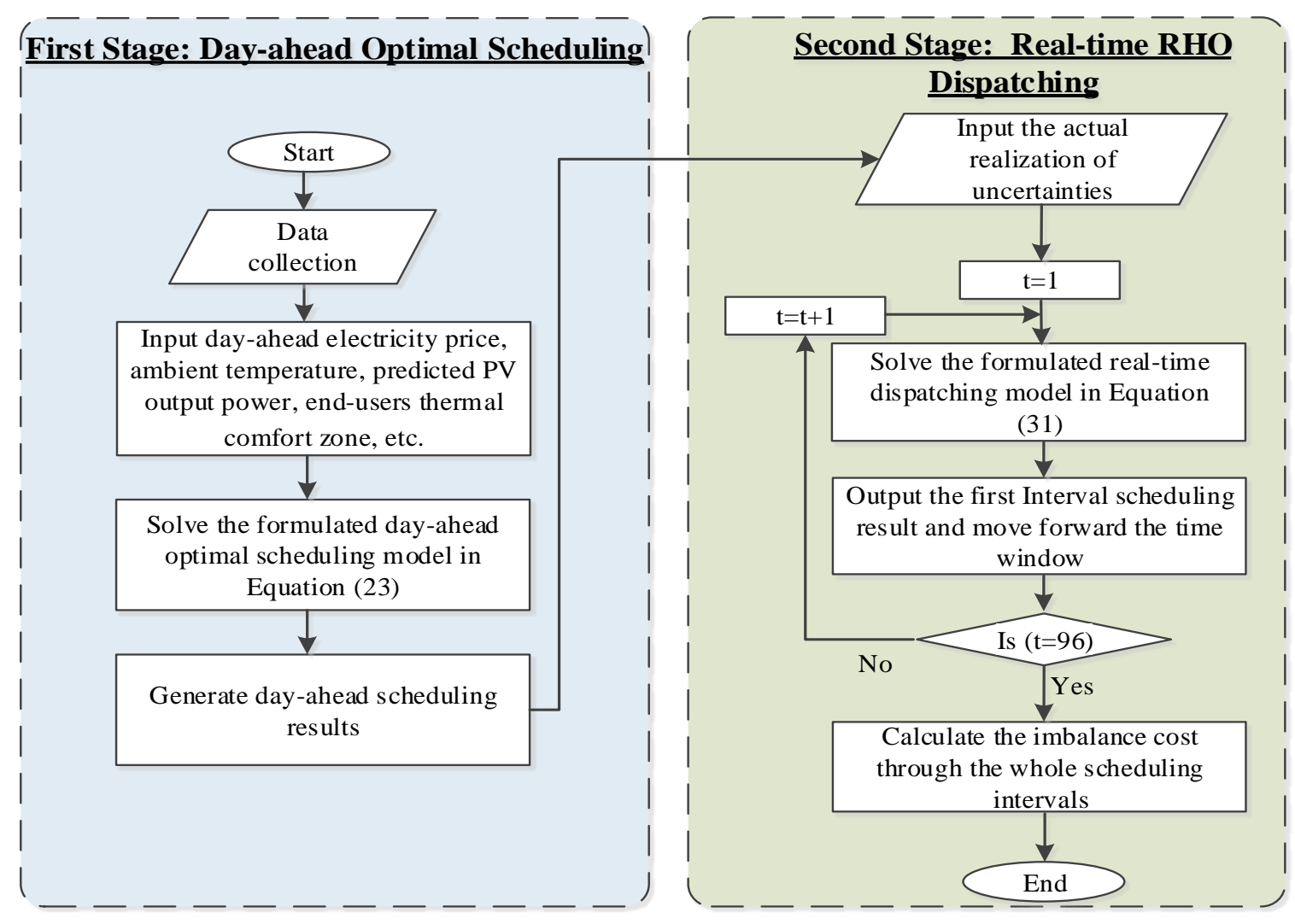

Fig. 4. Flowchart of two-stage optimal scheduling control scheme.

\section{Case Study}

\subsection{Setup}

In this work, the proposed control scheme is tested on Guangdong Fudian Data Center, which is comprised of internet data center (IDC) buildings and adjunct commercial buildings. The system configuration is shown in Fig. 5, which demonstrates the one-line diagram of the test system, including various devices and loads. Mosek toolbox embedded with MATLAB [32] is adopted here to solve the proposed large-scale mixed integer linear programming optimization problem.

In the test system, there is solar PV panel group and BESSs installed near the data center. The physical connection and information flow of these devices have been introduced in Section 2. Solar PV generation output power can be calculated by (11)-(13), based on the solar radiation collected from day-ahead solar data in Foshan, Guangdong [33] and ambient temperature. The equivalent rated output power of photovoltaic panels is set to $3000 \mathrm{~kW}$ here. The investment cost of BESS $I C^{E S}$ is defined as $80 E_{R}^{E S}$, BESS total life cycle number is 2000 times, BESS rated capacity is 3000 $\mathrm{kWh}$, initial capacity is $600 \mathrm{kWh}$, maximum charging/discharging power is $2400 \mathrm{~kW}$, the minimal and maximal allowed state of charge are set as $10 \%$ and $90 \%$, charging/discharging efficiency are 0.95 and 0.97 . The load in the test system includes lighting load, air-conditioning load, data server loads, etc. 
The building parameters and thermal comfort temperature ranges of five ACL groups are different. Table 1 shows the ranges for building parameters, AC rated power and temperature ranges, etc. It is assumed that building parameters (e.g. building size and wall thickness) and the rated power of air conditioners in a building are generated by Monte Carlo simulation to simulate the real-case scenario. In this work, differential evolution algorithm is adopted to calculate the aggregated capacity in each group, whose calculation methods can be found in [1] and will not be detailed here. It should be noted that the simulated ACL groups have diverse building units' numbers and different thermal comfort ranges. Air-conditioned rated power and building size are modelled by Monte Carlo simulation to consider parameter uncertainties.

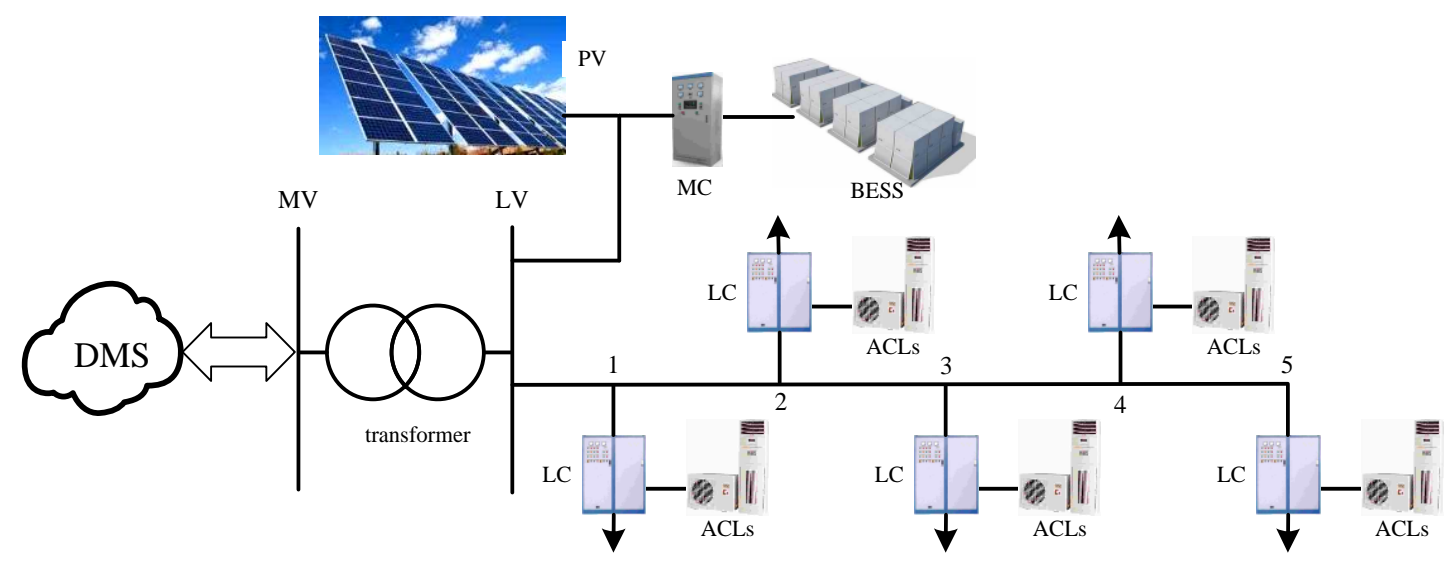

Fig. 5. Network configuration of the tested distribution network.

Table 1 ACL Group Sampling Ranges via Monte Carlo Simulation

\begin{tabular}{|c|c|c|c|c|c|c|}
\hline Group & $\begin{array}{l}\text { The amount of } \\
\text { building units in } \\
\text { every group }\end{array}$ & $\begin{array}{l}\text { Air conditioners } \\
\text { rated power } / \mathrm{kW}\end{array}$ & $\begin{array}{l}\text { Building length size /width } \\
\text { size/height size } / \mathrm{m}\end{array}$ & $\begin{array}{l}\text { The thickness } \\
\text { of wall } / \mathrm{m}\end{array}$ & $T_{r}^{\min } /{ }^{\circ} \mathrm{C}$ & $T_{r}^{\max } /{ }^{\circ} \mathrm{C}$ \\
\hline 1 & 120 & $3-7$ & $10-20 / 8-16 / 3.2$ & $0.2-0.4$ & 22 & 27 \\
\hline 2 & 100 & $3-7$ & $10-20 / 8-16 / 3.2$ & $0.2-0.4$ & 23 & 26 \\
\hline 3 & 140 & $3-7$ & $10-20 / 8-16 / 3.2$ & $0.2-0.4$ & 22 & 26 \\
\hline 4 & 180 & $3-7$ & $10-20 / 8-16 / 3.2$ & $0.2-0.4$ & 23 & 27 \\
\hline 5 & 150 & $3-7$ & $10-20 / 8-16 / 3.2$ & $0.2-0.4$ & 23 & 28 \\
\hline
\end{tabular}

The ambient temperature and electricity price in a typical summer day at Foshan, Guangdong are shown in Fig. 6. Daily load and PV generation output are given in Fig. 7. Please note that the daily load in Fig. 7 refers to the critical load in the system, i.e. data servers load, lighting load, without including air conditioning load. Real-time electricity purchase price, daily load and PV generation are given by the forecasting methods mentioned in the previous section. It should be known that, electricity selling price means solar PV resources feed-in tariff, which is lower than retail price. The solar PV feed-in tariff is around US\$ 0.055 . The peak electricity price is US\$ 0.196 , shoulder electricity price is US\$ 0.12 , and valley electricity price is US\$ 0.062 . The exchange rate is US\$ 1 $=¥ 6.9212$. As can be seen from Fig. 6, in one day, time period of 13:00-17:00 has peak ambient temperature. As for the peak electricity retail price, the time periods are mainly occupied by 11:0013:00 and 16:00-19:00. 

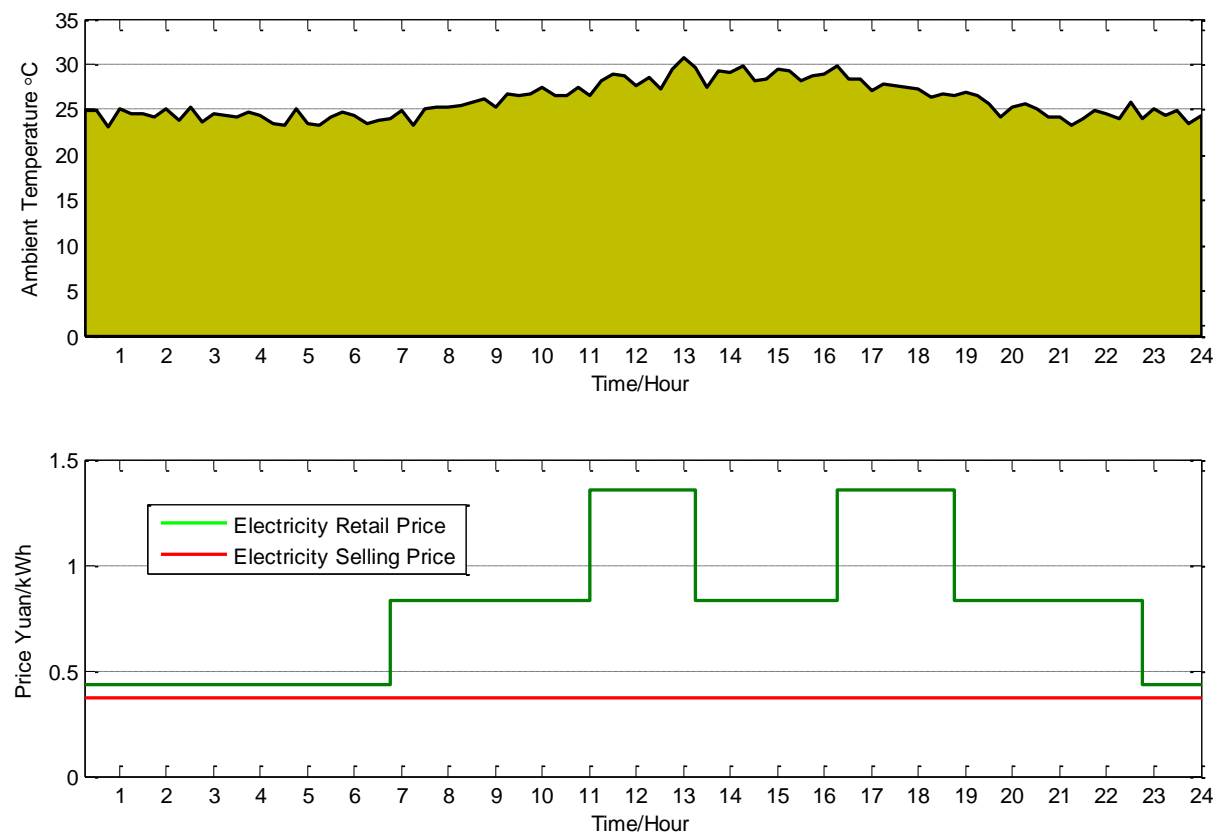

Fig. 6. Typical summer day ambient temperature and electricity price.

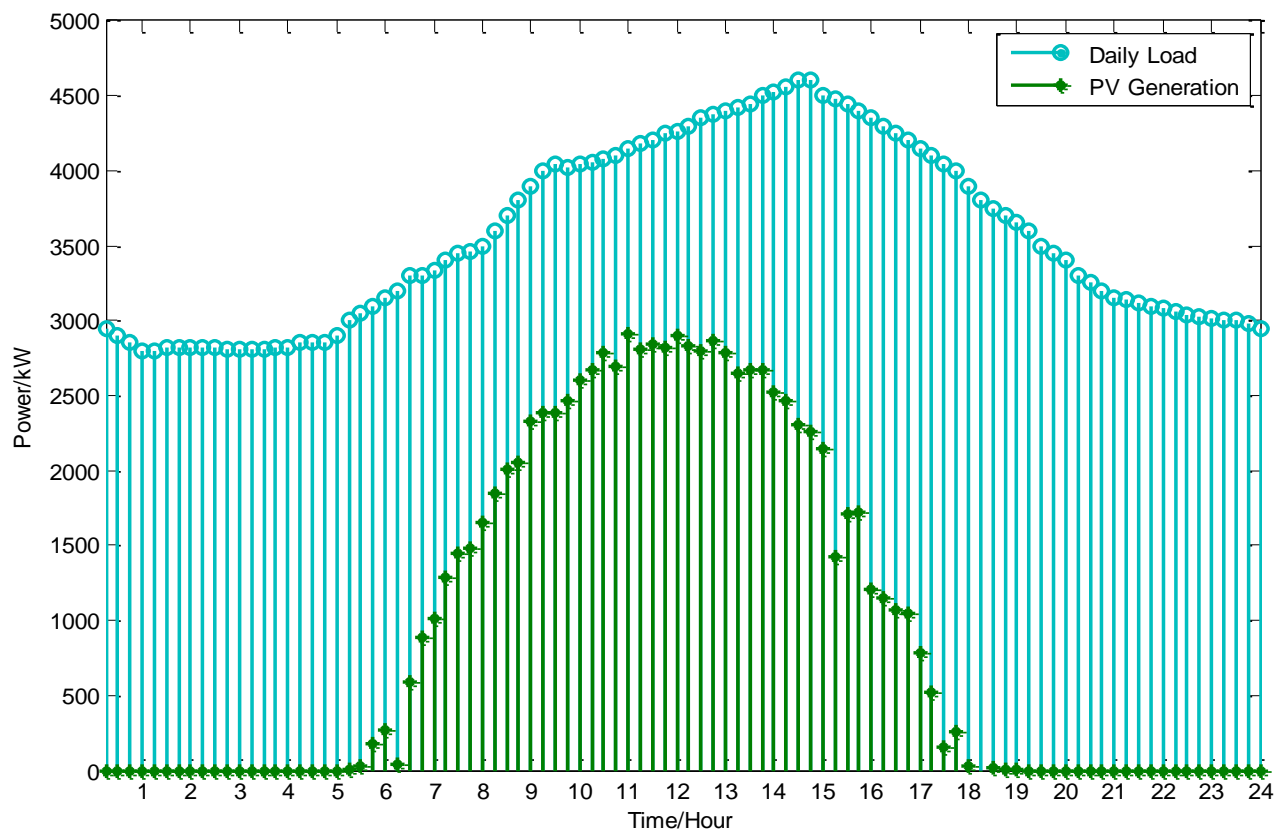

Fig. 7. Daily load and PV generation in test system.

\subsection{Simulation Results and Discussion}

Fig. 8 and Fig. 9 outline the day-ahead air conditioners' operation status in each group and the internal air temperature of each group in one day. Due to different building environments of ACL groups and defined thermal comfort ranges, the operation statuses of air conditioners in each group are quite different. From Fig. 9, it can be noted that the indoor temperature of the five groups is well controlled within the temperature ranges which are set before the optimization to satisfy the users' thermal comfort. 

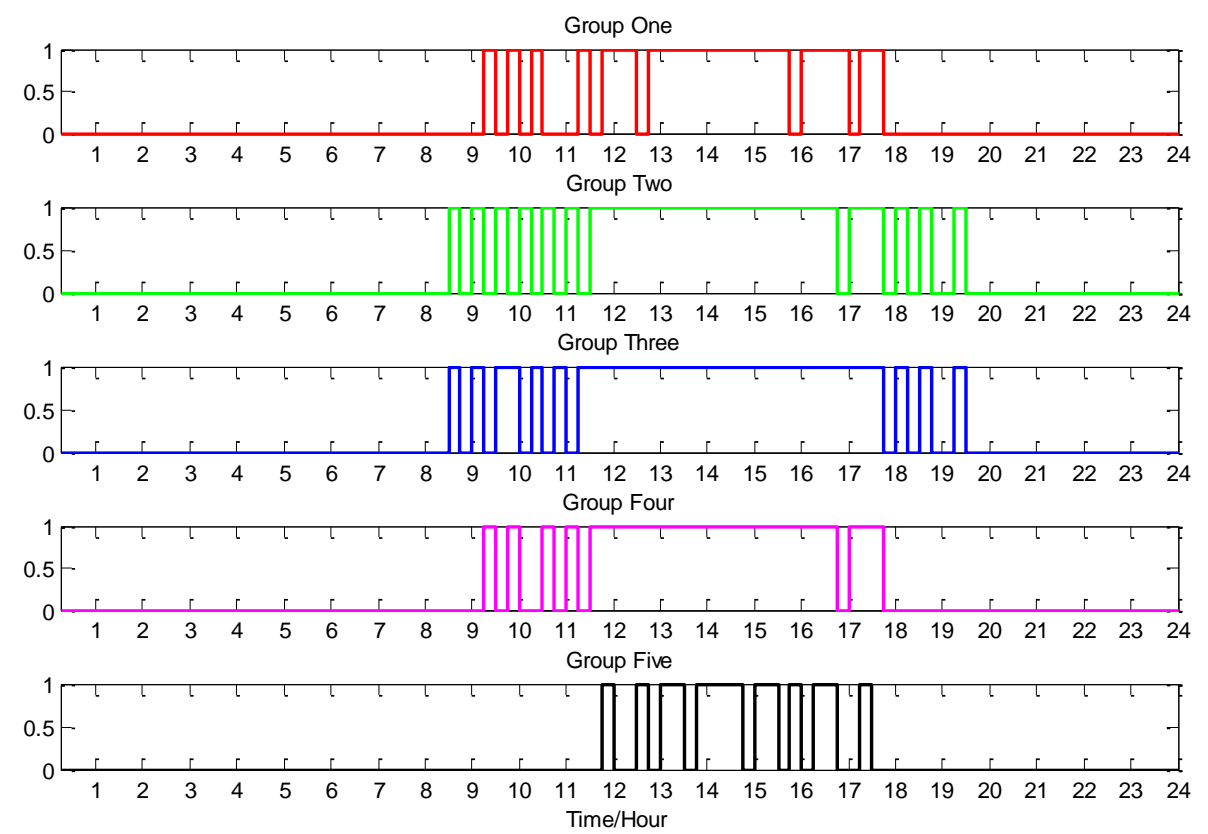

Fig. 8. The operation status of each group air conditioners in a day.

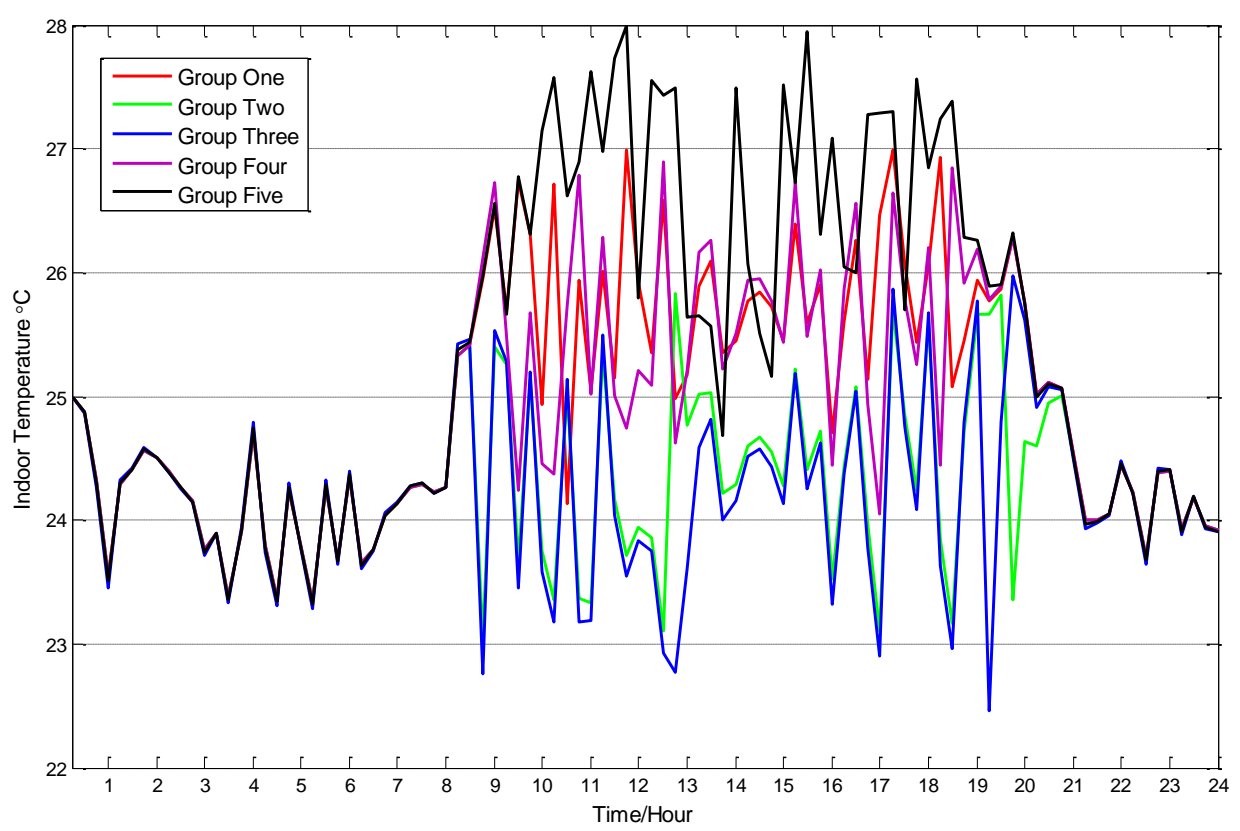

Fig. 9. Indoor temperature changes in each group in a day.

The power flow from BESSs to end users and the corresponding change in battery SOC are indicated in Fig. 10. The negative value in BESS power denotes that the battery is in charging status, and the positive value indicates the battery is in discharging status. It can be found that BESS is in discharging mode when the electricity retail price is relatively high. BESS is charged by solar PV panels when solar irradiation is strong and retail price is relatively low. It should be noted that PV power is completely consumed by charging BESSs or selling to external grid without curtailment during these periods. Therefore, solar power penetration level is improved through the proposed control scheme. 


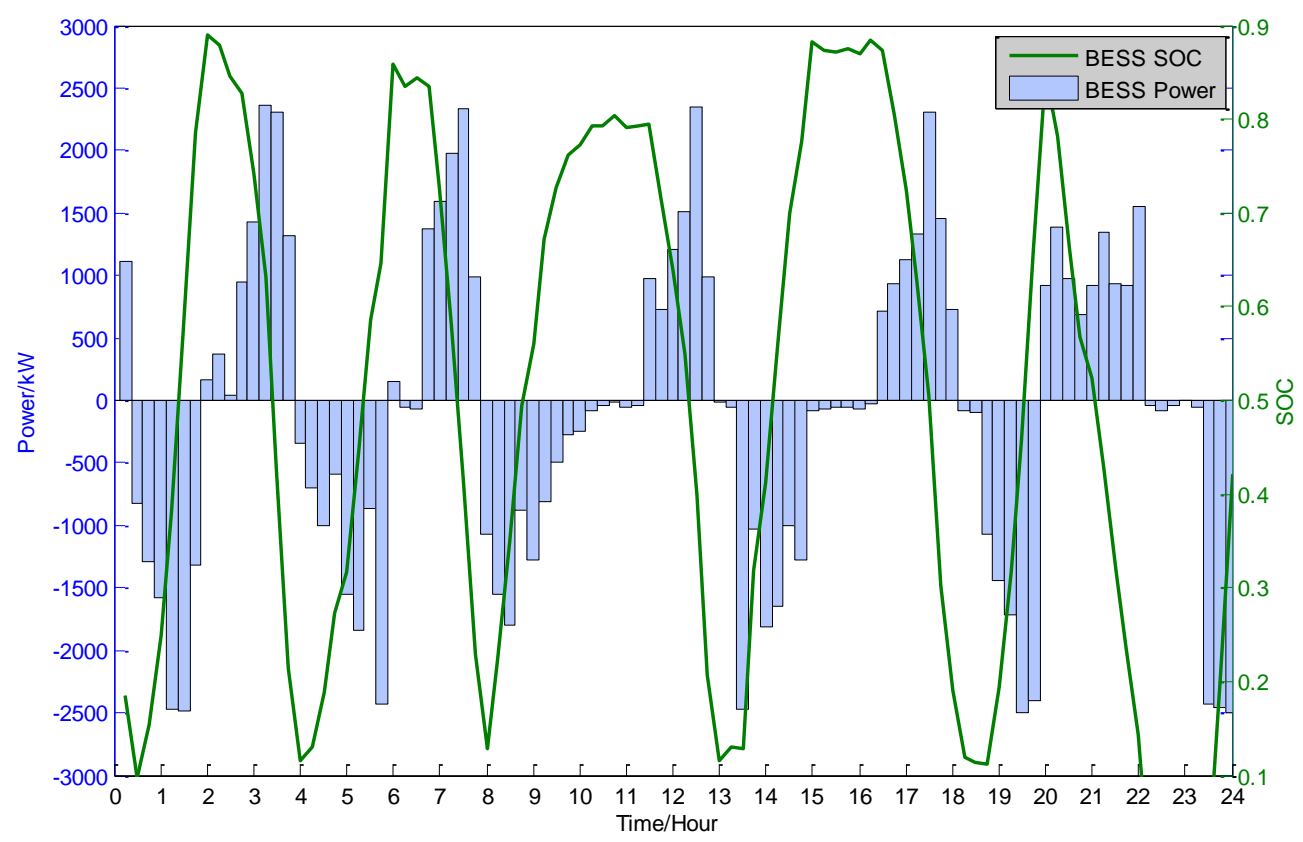

Fig. 10. Operation status of BESS.

Fig. 11 indicates the power exchange amount with external distribution network. As seen from the figure, the peak electricity purchase appears between 13:00-16:00, while the BESS works in charging status and electricity price is relatively low. In this period, due to high load demand and the decline of solar radiation, power from PV generation and BESS is not enough to meet the local requirements. Hence, external power purchase is conducted to meet system demand. Via coordinated scheduling of PV generation, BESS, and air conditioning resources in the system, peak demand is reduced as well as maintaining reliable system operation.

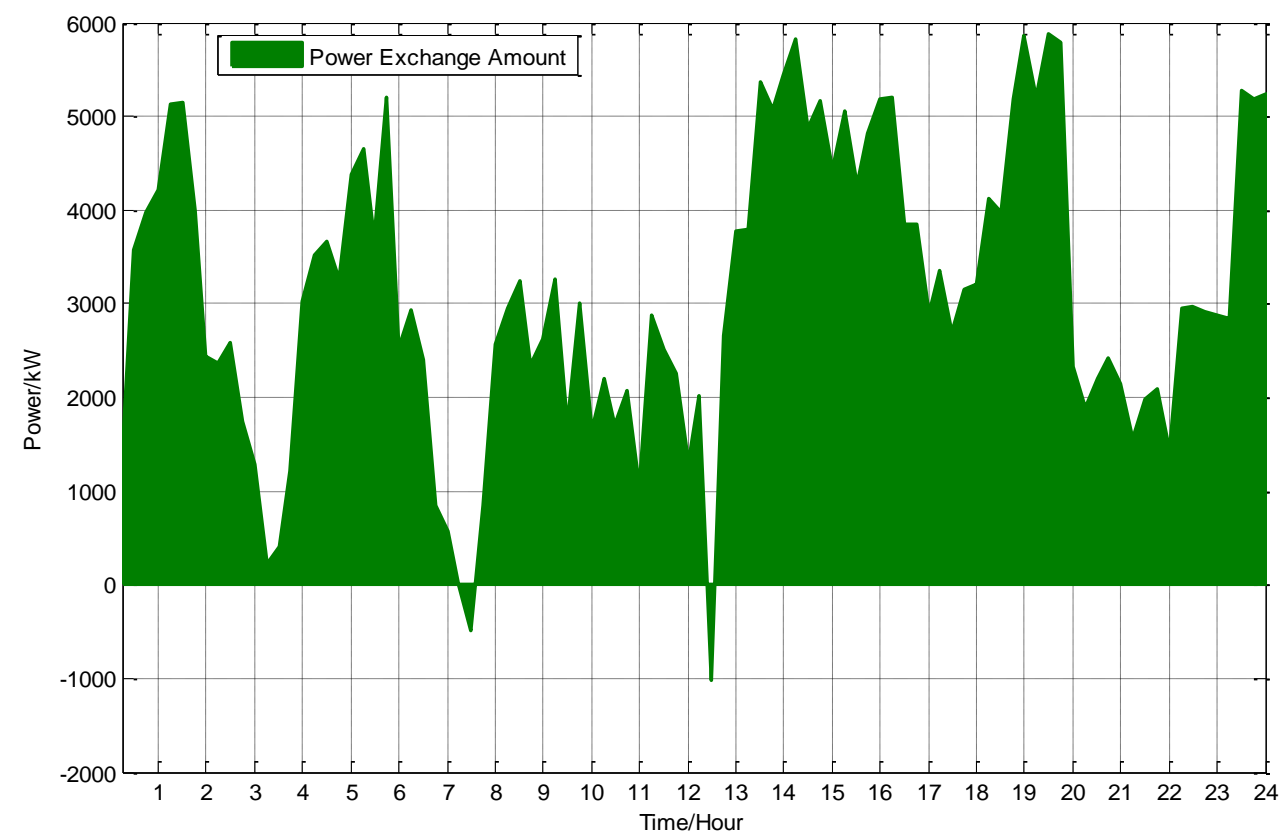

Fig. 11. Power exchange with distribution network. 
After getting day-ahead optimal scheduling results, real-time rolling horizon optimization approach is employed to alleviate the day-ahead forecast errors. Fig. 12 presents the real-time PV generation, daily load, and electricity retail prices, where day-ahead forecast data is given for comparison.

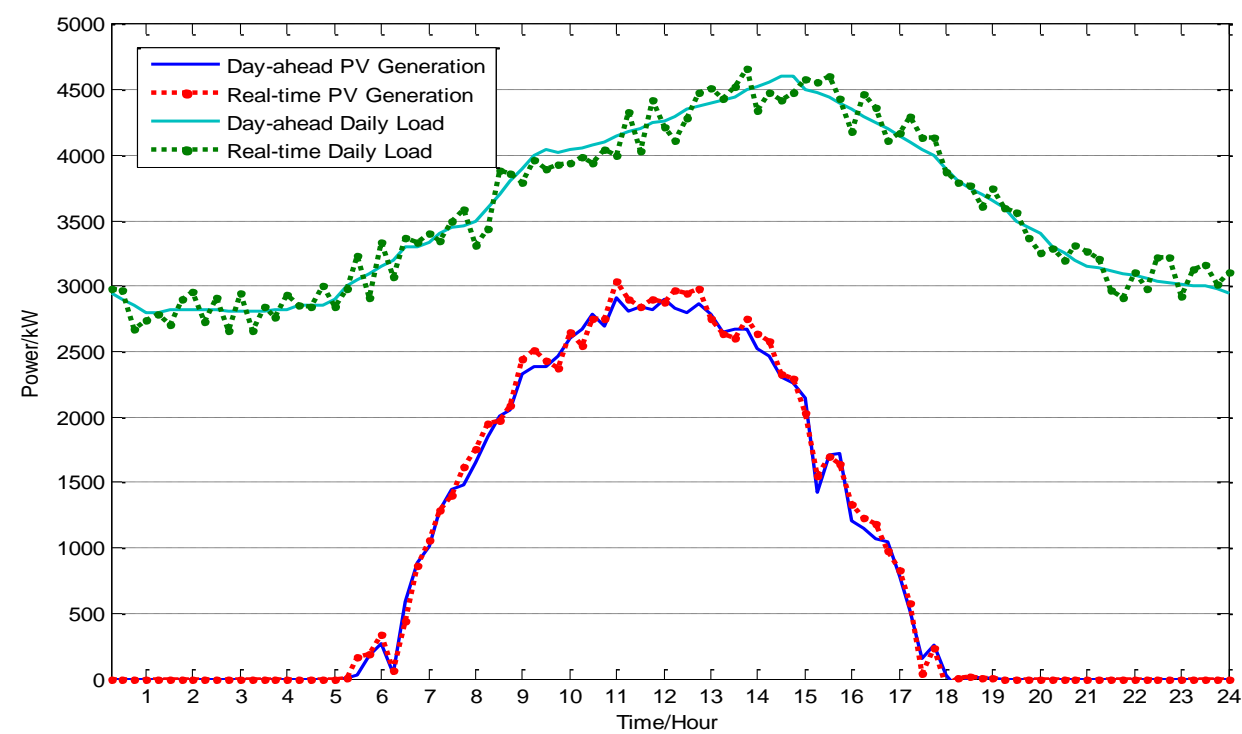

(a)

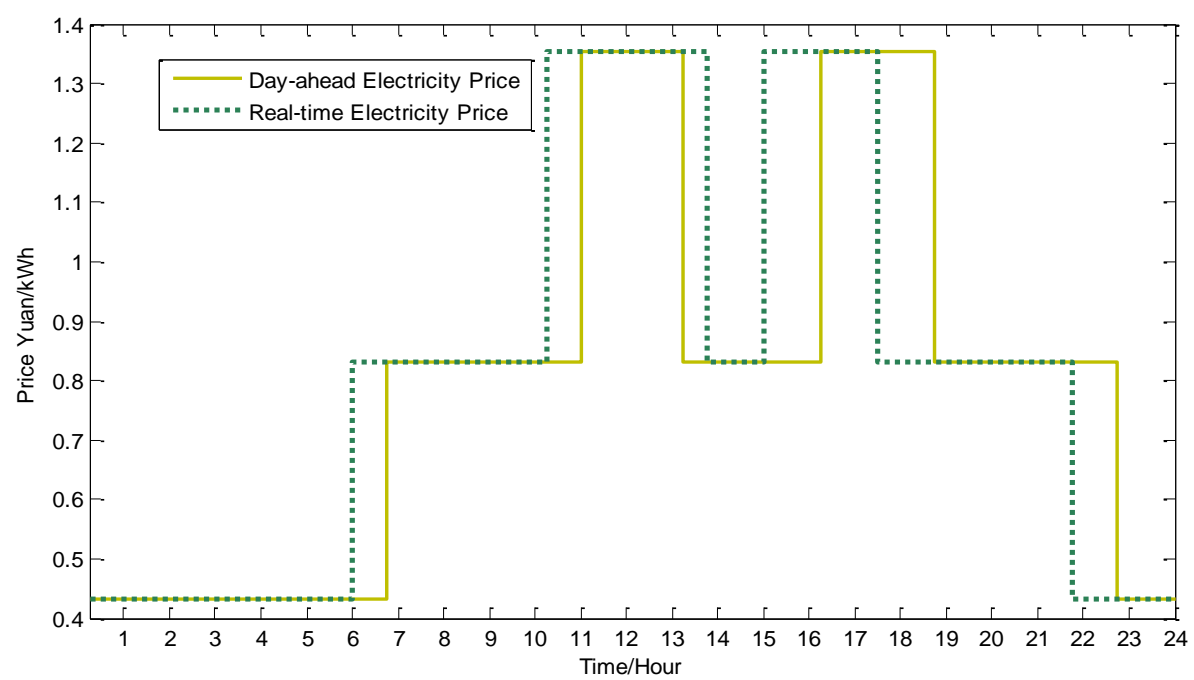

(b)

Fig. 12. Real-time daily load, PV generation, and electricity price: (a) Real-time daily load and PV generation; (b) Real-time electricity price.

Fig. 13 shows a comparison of the operating conditions of air conditioners. It can be seen that air conditioners are operated slightly different compared with day-ahead mode, to compensate for the forecast errors in day-ahead scheduling stage. At the same time, indoor temperatures are kept within the pre-defined ranges in both stages, which are not pictured here due to space limit, indicating the end users' thermal comfort is guaranteed. Fig. 14 presents the real-time stage power exchange amount, BESS power and BESS SOC. Similar to day-ahead scheduling results, BESS chooses to work in charging status at the moment when the retail price is relatively low and in discharging 
status at the moment when the retail price is relatively high.
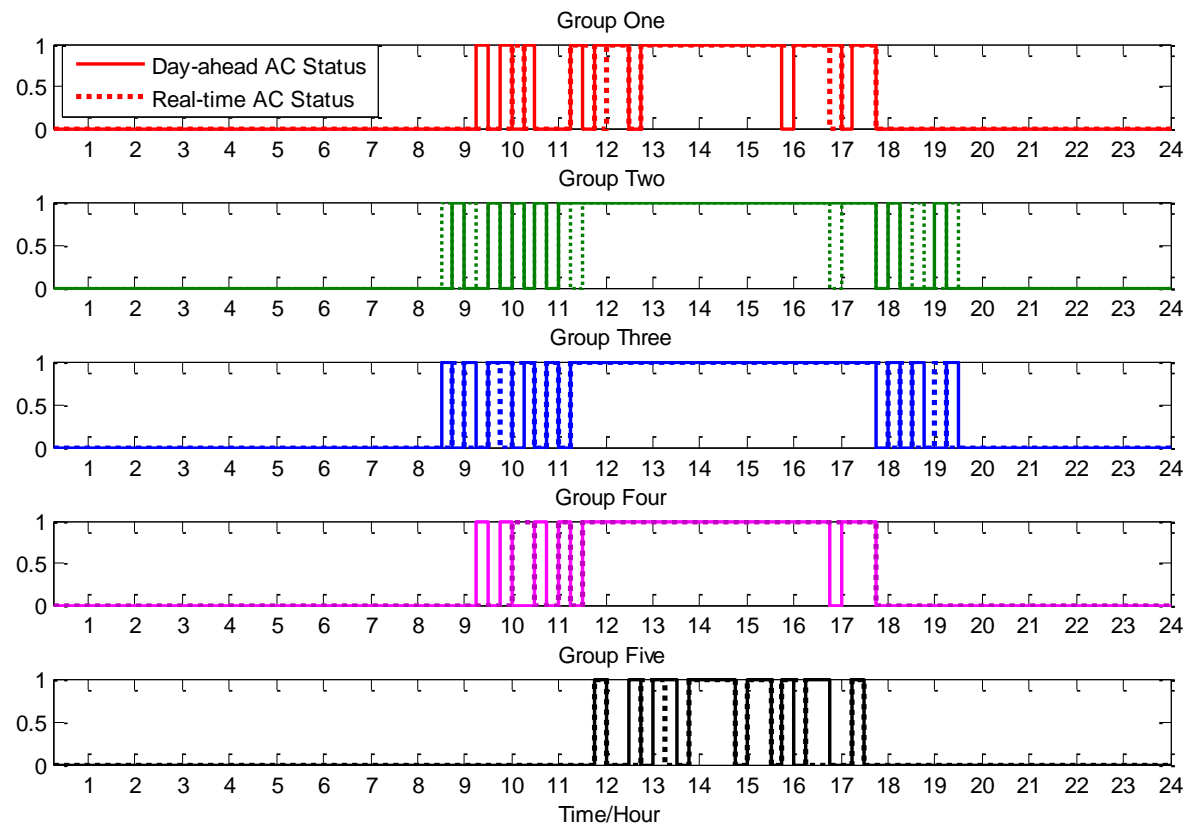

Fig. 13. Real-time air conditioners operation status in each group.

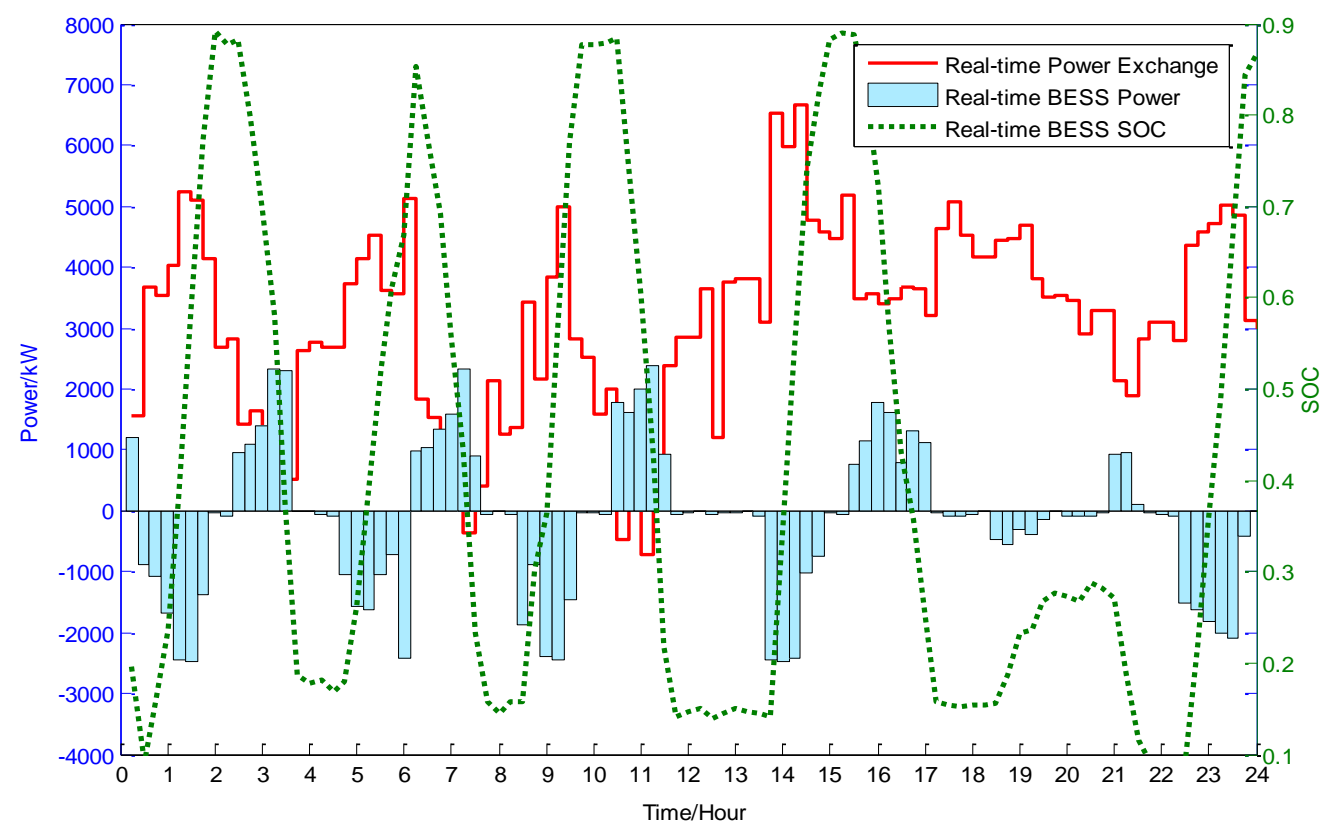

Fig. 14. Real-time power exchange with distribution network, BESS power, and BESS SOC.

To verify the economic efficiency of the proposed control scheme in this work, the daily operation cost of the test system is compared under three different scenarios, i.e. uncoordinated control, dayahead scheduling, and real-time control. Uncoordinated control means that the test system is consuming power directly from the external grid. As seen in Table 2, uncoordinated control scheme generates the highest operation cost, while day-ahead scheduling has the least cost. Owing to the existence of imbalance cost in real-time stage, its cost is slightly higher than day-ahead scheduling result, caused by alleviating the uncertainties in the system. 
Table 2 Operation cost comparison

\begin{tabular}{c|c|c|c}
\hline & Uncoordinated control & Day-ahead scheduling & Real-time control \\
\hline Operation cost & $¥ 43,767(\$ 6,324)$ & $¥ 31,915(\$ 4,611)$ & $¥ 28,798(\$ 4,161)$ \\
\hline Imbalance cost & 0 & 0 & $¥ 4,874(\$ 704)$ \\
\hline Net cost & $¥ 43,767(\$ 6,324)$ & $¥ 31,915(\$ 4,611)$ & $¥ 33,672(\$ 4,865)$ \\
\hline
\end{tabular}

(Exchange rate: $¥ 1=\$ 0.1445, \$ 1=¥ 6.9212$ )

\section{Conclusions and Future Work}

This paper puts forward a two-stage optimal scheduling method for distribution system under the situation of high photovoltaic penetration. A large-scale mixed integer linear programming control scheme is proposed to coordinate ACLs, PV and BESSs to minimize system operation cost in dayahead stage. To better meet end users' thermal comfort requirement, a novel and more precise twoparameter lumped thermal model is employed to describe the dynamic process of air-conditioned buildings. In real-time stage, uncertainties on PV generation, daily load and electricity price are considered to improve control accuracy. The objective in this stage aims to minimize the imbalance cost generated by the deviation between day-ahead electricity market and real-time electricity market. Simulation results validate that the minimum operation cost is generated while satisfying various system constraints. End users thermal comfort is guaranteed by keeping the indoor temperature into the required thermal comfort zone. In the meanwhile, the simulation results indicate that ACLs can be well scheduled to help integrating PV generation, and lowering the peak demand in distribution system.

Since there is an impact of occupant presence and behavior in buildings on space heating and cooling demand, future work would focus on addressing the impact of room occupancy rate on the thermal modelling, and present quantitative analysis as compared against the current thermal model. In addition, optimal sizing of PV generating systems and battery systems would be conducted to minimize the investment cost while satisfying technical and geographical constraints of the proposed control framework.

\section{Acknowledgements}

The work is co-sponsored by the Department of Finance and Education of Guangdong Province 2016 [202]: Key Discipline Construction Program, China; the Education Department of Guangdong Province: New and Integrated Energy System Theory and Technology Research Group [Project Number 2016KCXTD022]; and the research project under Guangdong Foshan Power Construction Corporation Group Co., Ltd. 


\section{References}

[1] Wang, D., Meng, K., Gao, X., Qiu, J., Lai, L. L., \& Dong, Z. Y. (2018). Coordinated dispatch of virtual energy storage systems in LV grids for voltage regulation. IEEE Transactions on Industrial Informatics, 14(6), 2452-2462.

[2] Graham, P. W., Hayward, J, Foster, J., Story, O. and Havas, L. 2018, GenCost 2018, CSIRO, Australia.

[3] Zhang, D., Wang, B., and Wang. Z. (2018). Renewable energy and politics: a systematic review and new evidence. Journal of Cleaner Production, 192, 553-568.

[4] Renewables 2018 Global Status Report - REN21, [Online]: http://www.ren21.net/wpcontent/uploads/2018/06/17-8652 GSR2018 FullReport web final .pdf $\quad$ (Accessed 03/02/2019)

[5] Pamparana, G., Kracht, W., Haas, J., and Roman, R., (2017). Integrating photovoltaic solar energy and a battery energy storage system to operate a semi-autogenous grinding mill. Journal of Cleaner Production, 165, 273-280.

[6] Lai, C.S., Jia, Y., Lai, L.L., Xu, Z., McCulloch, M.D. and Wong, K.P., (2017). A comprehensive review on large-scale photovoltaic system with applications of electrical energy storage. Renewable and Sustainable Energy Reviews, 78, 439-451.

[7] Clean Energy Council-Solar, [Online]: https://www.cleanenergycouncil.org.au/resources/technologies/solar-energy (Accessed 03/02/2019)

[8] Lin, C. H., Hsieh, W. L., Chen, C. S., Hsu, C. T., \& Ku, T. T. (2012). Optimization of photovoltaic penetration in distribution systems considering annual duration curve of solar irradiation. IEEE Transactions on Power Systems, 27(2), 1090-1097.

[9] Zhang, W., Lian, J., Chang, C. Y., \& Kalsi, K. (2013). Aggregated modeling and control of air conditioning loads for demand response. IEEE Transactions on Power Systems, 28(4), 46554664.

[10] Yan, C., Xue, X., Wang, S., \& Cui, B. (2015). A novel air-conditioning system for proactive power demand response to smart grid. Energy Conversion and Management, 102, 239-246.

[11] Song, M., Gao, C., Yan, H., \& Yang, J. (2017). Thermal battery modeling of inverter air conditioning for demand response. IEEE Transactions on Smart Grid, 9(6), 5522-5534.

[12] Alhaider, M., \& Fan, L. (2018). Planning energy storage and photovoltaic panels for demand response with heating ventilation and air conditioning systems. IEEE Transactions on Industrial Informatics, 14(11), 5029-5037.

[13] Wang, Q., Liao, J., Su, Y., Lei, C., Wang, T., \& Zhou, N. (2018). An optimal reactive power control method for distribution network with soft normally-open points and controlled airconditioning loads. International Journal of Electrical Power \& Energy Systems, 103, 421-430.

[14] Hui, H., Ding, Y., Liu, W., Lin, Y., \& Song, Y. (2017). Operating reserve evaluation of aggregated air conditioners. Applied Energy, 196, 218-228.

[15] Gagrica, O., Nguyen, P. H., Kling, W. L., \& Uhl, T. (2015). Microinverter curtailment strategy for increasing photovoltaic penetration in low-voltage networks. IEEE Transactions on Sustainable Energy, 6(2), 369-379.

[16] Zeraati, M., Golshan, M. E. H., \& Guerrero, J. M. (2018). Distributed control of battery energy 
storage systems for voltage regulation in distribution networks with high PV penetration. IEEE Transactions on Smart Grid, 9(4), 3582-3593.

[17] Yang, Y., Li, H., Aichhorn, A., Zheng, J., \& Greenleaf, M. (2014). Sizing strategy of distributed battery storage system with high penetration of photovoltaic for voltage regulation and peak load shaving. IEEE Transactions on Smart Grid, 5(2), 982-991.

[18] Chaudhary, P., \& Rizwan, M. (2018). Energy management supporting high penetration of solar photovoltaic generation for smart grid using solar forecasts and pumped hydro storage system. Renewable Energy, 118, 928-946.

[19] Akhavan-Rezai, E., Shaaban, M. F., El-Saadany, E. F., \& Karray, F. (2017). Managing demand for plug-in electric vehicles in unbalanced LV systems with photovoltaics. IEEE Transactions on Industrial Informatics, 13(3), 1057-1067.

[20] Zhu, R., De Carne, G., Deng, F., \& Liserre, M. (2017). Integration of large photovoltaic and wind system by means of smart transformer. IEEE Transactions on Industrial Electronics,64(11), 8928-8938.

[21] Luo, F., Dong, Z. Y., Meng, K., Wen, J., Wang, H., \& Zhao, J. (2017). An operational planning framework for large-scale thermostatically controlled load dispatch. IEEE Transactions on Industrial Informatics, 13(1), 217-227.

[22] Li, L., Chen, X. D., Tseng, M. L., and Kim. M. K., (2017). Effective power management modelling of aggregated heating, ventilation, and air conditioning loads with lazy state switching, Journal of Cleaner Production, 166, 844-850.

[23] Li W., Yang, L., Ji, Y., and Xu, P., (2019). Estimated demand response potential under coupled thermal inertia of building and air-conditioning system. Energy and Buildings, 182, 19-29.

[24] Wang, Y., Liu, Y., Wang, D., Liu, J., (2014). Effect of the night ventilation rate on the indoor environment and air-conditioning load while considering wall inner surface moisture transfer. Energy and Buildings, 80, 366-374.

[25] Liu, L., Zhao, Y., Chang, D., Xie, J., Ma, Z., Sun, Q., and Wennersten, R. (2018). Prediction of short-term PV power output and uncertainty analysis. Applied Energy, 228, 700-711.

[26] Wu, K., \& Zhou, H. (2014). A multi-agent-based energy-coordination control system for gridconnected large-scale wind-photovoltaic energy storage power-generation units. Solar Energy, 107, 245-259.

[27] Lai, C.S., Jia, Y., Xu, Z., Lai, L.L., Li, X., Cao, J. and McCulloch, M.D., (2017). Levelized cost of electricity for photovoltaic/biogas power plant hybrid system with electrical energy storage degradation costs. Energy conversion and management, 153, 34-47.

[28] Conejo, A. J., Carrión, M., \& Morales, J. M. (2010). Decision making under uncertainty in electricity markets (Vol. 1). New York: Springer.

[29] Xu, Y., Dong, Z. Y., Zhang, R., \& Hill, D. J. (2017). Multi-timescale coordinated voltage/var control of high renewable-penetrated distribution systems. IEEE Transactions on Power Systems, 32(6), 4398-4408.

[30] Qiu, J., Meng, K., Zheng, Y., \& Dong, Z. Y. (2017). Optimal scheduling of distributed energy resources as a virtual power plant in a transactive energy framework. IET Generation, Transmission \& Distribution, 11(13), 3417-3427.

[31] Fengji, L. U. O., Junhua, Z. H. A. O., Haiming, W. A. N. G., Xiaojiao, T. O. N. G., Yingying, C. H. E. N., \& Dong, Z. Y. (2014). Direct load control by distributed imperialist competitive algorithm. Journal of Modern Power Systems and Clean Energy, 2(4), 385-395. 
[32] MOSEK. The MOSEK optimization toolbox for MATLAB manual. Version 8.1.0.70. Available: https://docs.mosek.com/8.1/toolbox/index.html. (Accessed 12/3/2019).

[33] NASA solar data open portal, [Online]: https://data.nasa.gov/Earth-Science/SurfaceMeteorology-and-Solar-Energy/wn3p-qsan (Accessed 10/03/2019). 